\title{
Assessment of knowledge and reporting of adverse drug reaction in resident doctors in a teaching hospital in North India
}

\author{
Vaishalee Punj $^{1 *}$, Mushtaq Ahmad Hakeem ${ }^{2}$
}

${ }^{1}$ Department of Pharmacology, Punjab Institute of Medical Sciences, Jalandhar, Punjab, India

${ }^{2}$ Department of Pharmacology, Government Medical College, Doda, Jammu and Kashmir, India

Received: 27 November 2019

Revised: 31 December 2019

Accepted: 02 January 2020

\section{*Correspondence:}

Dr. Vaishalee Punj,

Email: shalupunj22@gmail.com

Copyright: (C) the author(s), publisher and licensee Medip Academy. This is an open-access article distributed under the terms of the Creative Commons Attribution Non-Commercial License, which permits unrestricted non-commercial use, distribution, and reproduction in any medium, provided the original work is properly cited.

\begin{abstract}
Background: This study was done to assess the knowledge, attitude and practices of residents towards pharmacovigilance in a teaching hospital in North India.

Methods: A cross-sectional study was conducted among residents of Chintpurni Medical College and Hospital, Pathankot $(\mathrm{CMC} \& \mathrm{H})$. A questionnaire containing 17 questions was distributed to 80 residents of $\mathrm{CMC} \& \mathrm{H}$, Pathankot. This study was conducted over a period of 3 months from July to September, 2017.

Results: 64 out of the 80 residents (80\%) responded to questionnaire. Among the respondents, $6 \%$ did not know the term adverse drug reaction (ADR) and almost $18 \%$ did not witness any ADR during clinical practice. Among those who witnessed ADRs nearly $25 \%$ could not ascertain the type of ADR. Those who ascertained ADRs claimed that upto $60 \%$ suspected ADRs required short hospitalisation. $6 \%$ residents did not consider ADRs avoidable and almost $25 \%$ residents did not consider ADRs predictable. $37 \%$ residents did not report the ADRs to anyone and nearly $43 \%$ did not know whom to report the ADRs. More than $18 \%$ claimed that they were not taught about PV in undergraduate curricular practical training teaching. Up to $31 \%$ residents claimed that nobody ever discussed with them about ADR reporting during internship.

Conclusions: According to this study, residents lack adequate knowledge and practice of reporting ADRs. This study suggests a greater need to create awareness amongst them to promote reporting of ADRs. This study also suggests that incorporation of Pharmacovigilance in medical curriculum will strengthen pharmacovigilance activity.
\end{abstract}

Keywords: Pharmacovigilance, Adverse drug reaction, Reporting, Knowledge, Residents

\section{INTRODUCTION}

Adverse drug reaction (ADR) is defined by WHO as a response to a drug which is noxious, unintended and occurs at doses normally used in man for the prophylaxis, diagnosis, or therapy of disease, or for the modifications of physiological function. ${ }^{1}$ Pharmacovigilance programme of a country depends on spontaneous reporting of ADR by healthcare professionals (HCPs). Under-reporting of ADRs is due to lack of knowledge, attitude and practices regarding pharmacovigilance among HCPs.

These days, new drugs are being developed and marketed at increasing rates. Many adverse drug reactions become evident once marketed medications are regularly used by patients post regulatory approval. ADRs have medical as well as economic consequences, leading to increased patient morbidity and mortality. ${ }^{2}$ Despite various control methods employed for quality, efficacy, and safety during 
drug development and manufacture, even in the most developed countries like USA, important new drugs had to be withdrawn within few years of their marketing (e.g., cerivastatin, cisapride, rofecoxib, valdecoxib, etc.) as their ADRs got reported. For better patient management, reporting of ADRs is an important step towards development of leads and signals that are monitored by Uppsala monitoring centre. ${ }^{3}$ Therefore it has become important to report any ADR occurring after marketing of the drug.

In studies conducted across many countries, it has become apparent that under-reporting of ADRs is a major health concern. Most developed countries have wellestablished ADR reporting system. These systems have been developed for reporting by healthcare professionals including doctors, pharmacists, nurses, etc and also by consumers like patients, family members, lawyers etc. ${ }^{4}$ In most developing countries, pharmacovigilance is still a relatively new concept and pharmacovigilance programs are still in infancy. However, there is considerable underreporting in developed as well as developing countries. ${ }^{5}$ In India, National Coordination Centre-Pharmacovigilance program of India (NCC-PvPI) is working under guidance of Central Drugs Standard Control Organization (CDSCO), Directorate General of Health Services, Ministry of Health and Family Welfare, Government of India since 2010. As per recent data, 179 Medical Council of India (MCI) approved teaching hospitals have been identified as ADR monitoring centres (AMCs) across the country. ${ }^{6}$ Despite their efforts in establishing ADR monitoring centres in many hospitals, pharmacovigilance in India is still in its infancy.

Many reasons have been implicated for under-reporting of ADRs. Studies suggest lack of knowledge about ADRs, lethargy, insecurity, diffidence, complacency, indifference, workload and inadequate training in Pharmacovigilance among healthcare professionals to be important reasons responsible for under-reporting in Indian hospitals. ${ }^{7}$ Acknowledging the importance to assess knowledge, attitudes, and practices (KAP) of healthcare professionals toward ADR reporting, this study was designed to assess the three quotients (KAP) in residents of a teaching hospital in North India. We hope that the results of this study will inform policy makers on best practices for ADR reporting in India.

\section{METHODS}

A cross-sectional questionnaire-based study was carried out in Chintpurni Medical College and Hospital (CMC\&H), Punjab, India which is a teaching and tertiary care hospital. This study was conducted over a period of 3 months from July 2017 to September 2017.

Any resident doctor involved in prescribing, dispensing and administration of drugs to a patient was eligible for inclusion. A structured questionnaire was prepared based on the work of Upadhyaya et al with minor modifications. ${ }^{8}$ The questionnaire sought information regarding participants' demographics, awareness about the term ADR, knowledge of ADR reporting, ADR management during their residency and Pharmacovigilance teaching sessions about ADRs during their under-graduate curricular practical training (CPT) teaching. Also, suggestions on the possible ways to improve the ADR reporting were sought. Most of the questions in the questionnaire were objective type and mostly required a "yes" or "no" response (Appendix). ${ }^{8}$

The questionnaire containing 17 questions was presented to 80 resident doctors of $\mathrm{CMC} \& \mathrm{H}$ willing to participate in the study. After explaining the purpose of study, 30 minutes time was allowed to fill the questionnaire. Filling the questionnaire was taken as consent for the study. Unit nonresponse questionnaires were not included whereas single term non response questionnaires were included in analysis. The KAP questionnaire was analysed for each question and percentages were calculated for the given choices.

\section{RESULTS}

Out of the 80 residents to whom the questionnaire was administered, a total of 64 were filled. The response rate of the survey was $80 \%$. Characteristics of participant residents are shown in Table 1 . Upto $44 \%$ residents were in the age group of 26-30 years. 52 males and 12 female residents participated in the study (Table 1). The participating residents did their undergraduate training in various teaching hospitals of North India including SKIMS, Soura Srinagar, ASCOMS \& Hospital, Jammu, Government Medical College, Amritsar, Government Medical College, Jammu and other teaching hospitals in descending order. Up to $94 \%$ residents claimed to already know the word adverse drug reaction (ADR) (Table 1).

Knowledge about witnessed ADRs is shown in Figure 1. In our study, up to $19 \%$ residents did not witness any ADRs. Among those who witnessed ADRs, 31\% claimed that likely cause of ADR was idiosyncratic reaction, 19\% said that ADR was due to drug interaction, $12.5 \%$ was due to medication error, $6.25 \%$ was due to allergic reaction, $6.25 \%$ was due to hypersensitivity reaction. However, 25\% did not respond to the question (Figure 1). Among those who witnessed ADRs, 60\% ADRs required short hospitalization, $12.5 \%$ ADRs caused morbidity, $6 \%$ ADRs were mild enough to not require hospitalization. Upto $19 \%$ residents did not respond to question (Figure 1).

Knowledge of residents about avoid ability and predictability of ADRs is depicted in Figure 2. Up to $94 \%$ residents considered ADRs to be avoidable and up to $69 \%$ residents considered ADRs to be predictable (Figure 2). 
Table 1: Characteristics of residents participating in the survey.

\begin{tabular}{|c|c|c|}
\hline Question & Parameter & $\mathbf{N}(\%)$ \\
\hline \multirow{3}{*}{ How old are you? } & $21-25$ yrs & $20(31.25)$ \\
\hline & $26-30 \mathrm{yrs}$ & $28(43.75)$ \\
\hline & $31-35$ yrs & $16(25)$ \\
\hline \multirow{2}{*}{ What is your gender? } & Female & $12(18.75)$ \\
\hline & Male & $52(81.25)$ \\
\hline \multirow{8}{*}{$\begin{array}{l}\text { Where did you do your undergraduate } \\
\text { medical training? }\end{array}$} & Adesh Medical College, Bathinda & $4(6.25)$ \\
\hline & ASCOMS and Hospital, Jammu & $10(16.625)$ \\
\hline & Dayanand Medical College, Ludhiana & $4(6.25)$ \\
\hline & Government Medical College, Amritsar & $9(14.06)$ \\
\hline & Government Medical College, Jammu & $8(12.5)$ \\
\hline & Others & $3(4.68)$ \\
\hline & Lady Hardinge Medical College, New Delhi & $2(3.125)$ \\
\hline & SKIMS, Soura Srinagar & $24(37.5)$ \\
\hline \multirow{2}{*}{ Did you know the term ADRs before? } & Yes & $60(93.75)$ \\
\hline & No & $4(6.25)$ \\
\hline
\end{tabular}

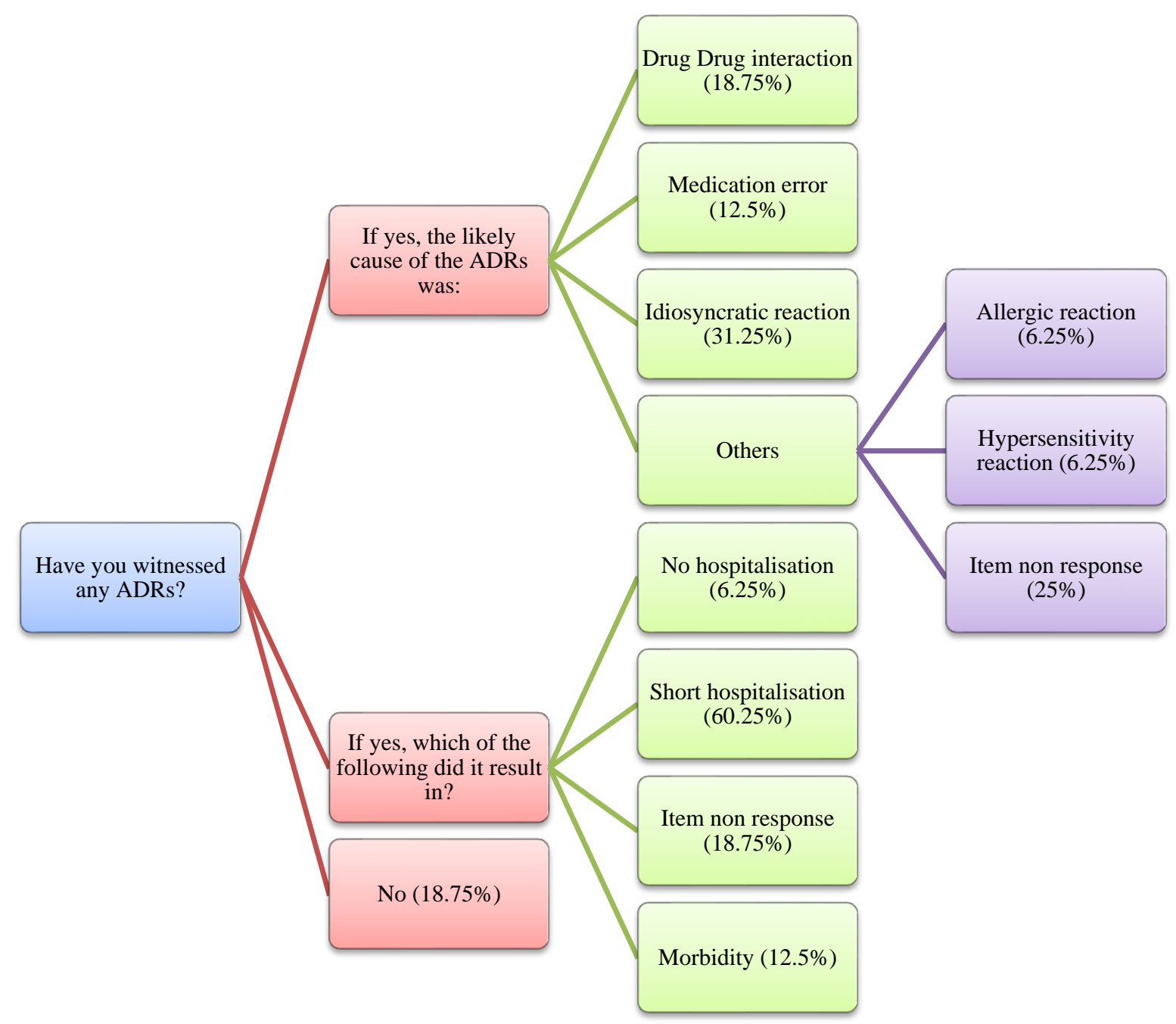

Figure 1: Knowledge about witnessed ADRs.

Reporting practices of ADRs of residents was shown in Figure 3. More than $37 \%$ residents did not report the ADRs and $6 \%$ did not respond to the question. Among those who reported ADRs, upto 44\% reported to head of department, $12.5 \%$ reported ADRs to ADR monitoring committee of hospital and none of them reported to national pharmacovigilance centre (Figure 3). 


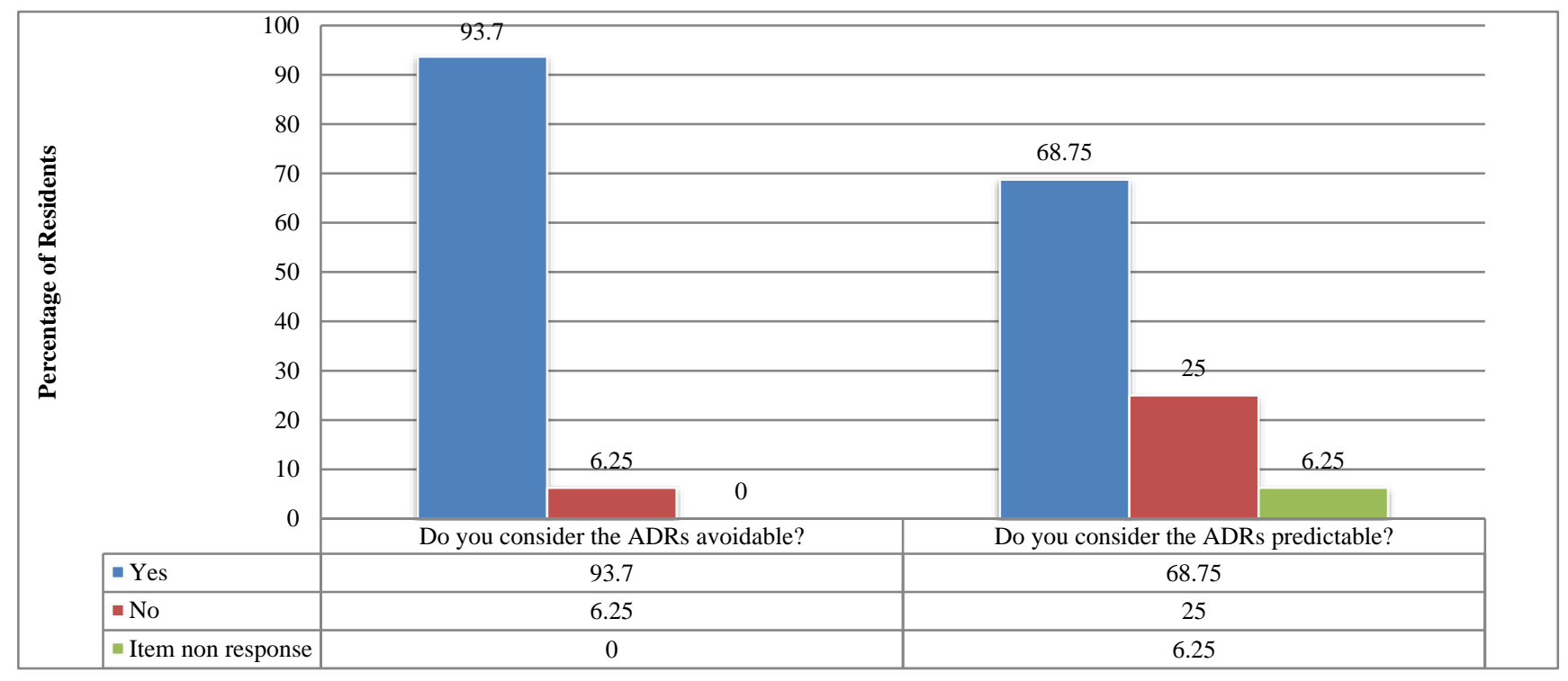

Figure 2: Knowledge of residents about avoid ability and predictability of ADRs.

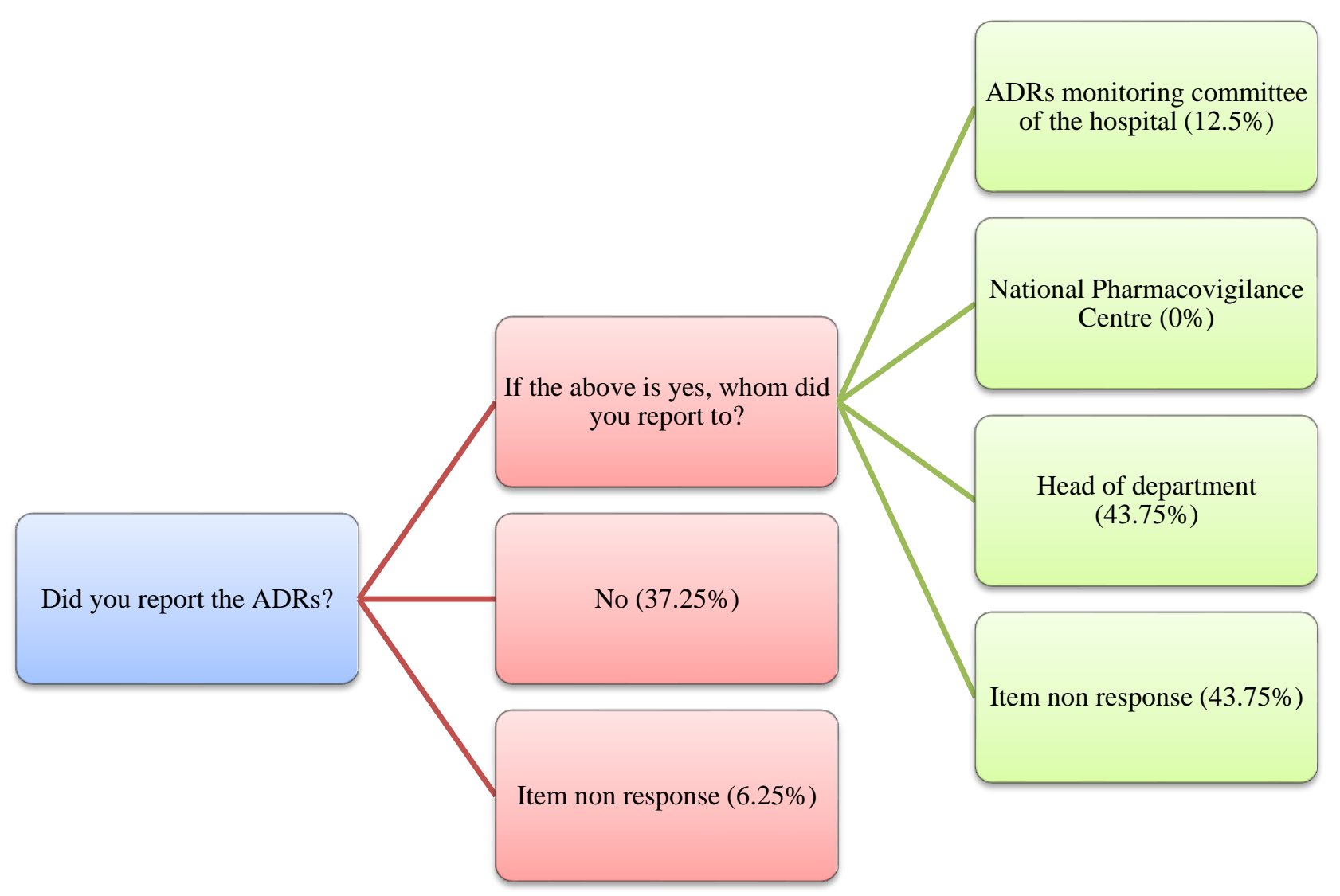

Figure 3: Reporting practice of ADRs of residents.

Figure 4 shows undergraduate Teaching of residents about ADRs and ADR reporting. Upto $19 \%$ residents were not taught about reporting procedure of ADR in undergraduate CPT teaching. All participants agreed that a good knowledge of undergraduate CPT teaching would have improved the ADR reporting. 31\% residents stated that no one ever discussed ADR reporting with them during internship training. 25\% residents did not know about PvPI (Figure 4). 


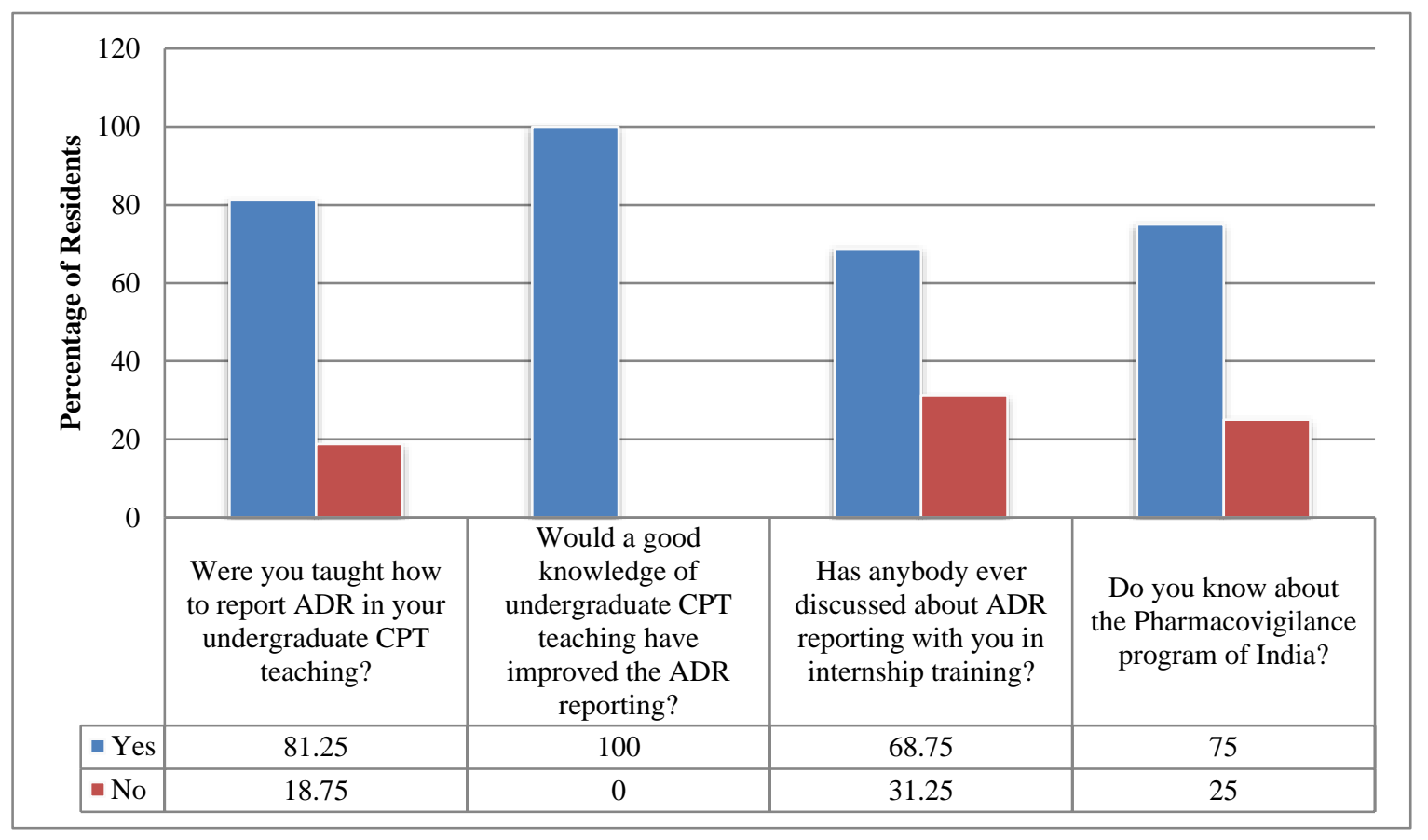

Figure 4: Undergraduate CPT teaching in pharmacovigilance.

Majority of the residents suggested to increase teaching about Pharmacovigilance during undergraduate training in clinical pharmacology and therapeutics and they believed that it will improve competency in ADR reporting. 32\% residents suggested to conduct regular training of healthcare workers about ADRs and PvPI. 32\% residents suggested formation of well-established and functioning ADR reporting centre in all teaching hospitals including CMC\&H, Pathankot. This suggestion is understandable as ADR monitoring centre was in its infancy in this institute. $19 \%$ residents suggested undergraduate training about ADRs to be made mandatory. $12.5 \%$ residents suggested to raise awareness about use of generic medication. $12.5 \%$ residents suggested training of healthcare workers about drug-drug interactions. $7 \%$ residents suggested adopting ways to encourage reporting of ADRs among healthcare workers. $7 \%$ residents suggested making reporting of ADRs to Head of Department or ADR reporting centre mandatory by law.

\section{DISCUSSION}

Although, these residents seemed to know the term ADR, and also acknowledged the importance of ADR reporting, most of them lacked knowledge on ADRs and the process of ADR reporting: what, where and how to report. This is not only undesirable but also detrimental to patient management. Therefore, efforts should be undertaken to create awareness about ADR reporting among medical students and HCPs.

In our study, most of the residents who completed questionnaire were males in the age group of 26 to 30 years. The age and gender demographics of participants are in concordance with studies conducted elsewhere in India. ${ }^{9}$

In our study the participating residents did their undergraduate training in various teaching hospitals of North India and many claimed to have prior knowledge of the word ADR. Similarly, various studies have reported high awareness of the term ADR and pharmacovigilance. Agarwal et al observed in their KAP study that more than $70 \%$ of healthcare providers in a teaching hospital in India were aware of the term pharmacovigilance. ${ }^{10} \mathrm{HCPs}$ seem to be aware of the term ADR.

However, we found that residents in this hospital had low knowledge about causes and types of ADRs. In this study many residents did not witness any ADRs. Among those who witnessed ADRs, majority claimed that they were idiosyncratic reactions (a genetically determined, rare reaction). On the contrary, studies have revealed that most reactions are augmented reactions that are due to a property of the drug. ${ }^{11}$

We found that hospitalized ADRs were being reported more frequently and non-serious and mild ADRs were ignored and not reported. This finding is in concordance with studies conducted elsewhere. ${ }^{12}$ However it is a known medical fact that mild and non-serious ADRs happen most frequently. ADRs that seem common and mild to doctors, may be a cause of significant discomfort to patient and they should be reported as well. This shows the attitude of diffidence and complacency towards reporting of non-serious ADRs.

Most residents considered ADRs to be predictable and avoidable. This finding is in concordance with findings in 
studies conducted elsewhere. ${ }^{8}$ Nair has suggested in his study that only upto $28 \%$ ADRs are considered unavoidable. ${ }^{13}$ The causes of avoidable ADRs could be inappropriate prescription, wrong dosage, missed drug interactions, missed past history of ADRs to the drug in a patient or reexposure to the allergen in known drug allergies. Nair also suggests that it is difficult to predict ADRs due to many reasons like vague presentation of ADRs and presence of comorbid conditions. ${ }^{13}$ Only $25 \%$ residents in our study considered ADRs to be unpredictable. This suggests low knowledge in these residents about predictability and avoid ability of ADRs.

We found that majority of residents did not witness or failed to report the witnessed ADRs. Among those who reported ADRs, some reported to head of department and others reported to ADR monitoring centre of hospital..$^{8,14}$ Resident may have been doing their best to clinically manage the patient but they mostly failed to recognize and report the ADR. This depicts that residents did not know how to act if they witnessed an ADR in their department. For every unreported ADR, UMC loses its chance to raise signal or alert for the medicine. Also, the affected patient fails to get proper management of health condition.

We found that many residents were not taught about reporting procedure of ADR in undergraduate CPT teaching or in internship. ${ }^{8,15}$ It didn't come as a surprise when a significant number of residents mentioned that they did not know about PvPI. ${ }^{16}$ All participants agreed that a good knowledge of undergraduate CPT teaching would increase the number of ADR reports and lessen the mistakes made during filling of ADRs forms. They have shown amazing willingness to know more about ADR reporting skills. They have also expressed the need for well-established and properly functioning ADR monitoring centers in this and other teaching hospitals.

The results of this study are showing the limited proficiency in pharmacovigilance knowledge, attitude and skills among residents in this teaching hospital and can suitably be generalized to other teaching hospitals in India and other countries. India has launched the PvPI in 2010 with a vision to improve patient safety and welfare in Indian population by monitoring drug safety. ${ }^{17}$ Many institutes including government and private institutes in India have also started pharmacovigilance training programs. Including pharmacovigilance in undergraduate CPT curriculum seems the most effective tool to train future doctors. Starting and propagating innovative methods like pharmacovigilance app in smart phone should also increase reporting.

\section{CONCLUSION}

Our study has revealed a big deficiency in knowledge, attitude and practice of ADR reporting by residents in a teaching hospital in North India. According to our study, most ADRs go un-recognized and un-reported and it demonstrates inadequacy of pharmacovigilance activities in hospitals. Many methods have been suggested to overcome these problems like conducting regular pharmacovigilance teaching during undergraduate CPT curriculum and thereafter in hospitals. However implementing these suggestions require strenuous and consistent efforts by administrative services in PvPI and hospitals. Considering the importance of the drug safety of patients, ADR reporting should be made mandatory in India.

\section{ACKNOWLEDGEMENTS}

Authors would like to thank Chintpurni Medical College and Hospital, Pathankot, Punjab, India.

Funding: No funding sources

Conflict of interest: None declared

Ethical approval: Not required

\section{REFERENCES}

1. WHO. Adverse reaction. WHO, 1972. Available at: http://www.who.int/medicines/areas/quality_safety/sa fety_efficacy/trainingcourses/definitions.pdf.

Accessed on 30 October 2019.

2. Giardina C, Cutroneo PM, Mocciaro E, Russo GT, Mandraffino G, Basile G, et al. Adverse Drug Reactions in Hospitalized Patients: Results of the FORWARD (Facilitation of Reporting in Hospital Ward) Study. Front Pharmacol. 2018;9:350.

3. Lindquist M. VigiBase, the WHO Global ICSR Database System: basic facts. Drug Inf J. 2008;42(5):409-19.

4. FDA. Questions and Answers on FDA's Adverse Event Reporting System (FAERS). Available at: https://www.fda.gov/drugs/surveillance/questionsand-answers-fdas-adverse-event-reporting-systemfaers. Accessed on 4 November 2019.

5. Stergiopoulos S, Brown CA, Felix T, Grampp G, Getz KA. A Survey of Adverse Event Reporting Practices Among US Healthcare Professionals. Drug Saf. 2016;39(11):1117-27.

6. Kalaiselvan V, Thota P, Singh GN. Pharmacovigilance Programme of India: Recent developments and future perspectives. Indian $\mathbf{J}$ Pharmacol. 2016;48(6):624-8.

7. Tandon VR, Mahajan V, Khajuria V, Gillani Z. Under-reporting of adverse drug reactions: a challenge for pharmacovigilance in India. Indian $\mathbf{J}$ Pharmacol. 2015;47(1):65-71.

8. Upadhyaya P, Seth V, Moghe VV, Sharma M, Ahmed M. Knowledge of adverse drug reaction reporting in first year postgraduate doctors in a medical college. Ther Clin Risk Manag. 2012;8:30712.

9. Baitha U, Ranjan P, Sarkar S, Arora C, Kumari A, Dwivedi SN, et al. Development of a self-assessment tool for resident doctors' communication skills in India. J Educ Eval Health Prof. 2019;16:17. 
10. Agarwal M, Ahmed J, Roy V. Knowledge, Attitude, and Practice About Pharmacovigilance Among Healthcare Providers of a Tertiary Care Teaching Hospital in New Delhi (India). MAMC J Med Sci. 2017;3:146-51.

11. Sundaran S, Udayan A, Hareendranath K, Eliyas B, Ganesan B, Hassan A, et al. Study on the Classification, Causality, Preventability and Severity of Adverse Drug Reaction Using Spontaneous Reporting System in Hospitalized Patients. Pharmacy (Basel). 2018;6(4):108.

12. Nisa ZU, Zafar A, Sher F. Assessment of knowledge, attitude and practice of adverse drug reaction reporting among healthcare professionals in secondary and tertiary hospitals in the capital of Pakistan. Saudi Pharm J. 2018;26(4):453-61.

13. Nair PN, Chalmers L, Peterson MG, Bereznicki B, Castelino LR, Bereznicki L. Hospitalization in older patients due to adverse drug reactions - the need for a prediction tool. Dovepress. 2016;11;497-505.

14. Sharma PK, Singh S, Dhamija P. Awareness among tertiary care doctors about Pharmacovigilance
Programme of India: Do endocrinologists differ from others?. Indian J Endocr Metab. 2016;20:343-7.

15. Schutte T, Tichelaar J, Reumerman MO, Eekeren R V, Rissmann R, Kramers C, et al. Pharmacovigilance Skills, Knowledge and Attitudes in our Future Doctors - A Nationwide Study in the Netherlands. Basic Clin Pharmacol. 2017;120:475-81.

16. Shankar PR, Subish P, Mishra P, Dubey AK. Teaching pharmacovigilance to medical students and doctors. Indian J Pharmacol. 2006;38:316-9

17. Guidance Document For Spontaneous Adverse Drug Reaction Reporting Version: 1.0. Available at: http://apps.who.int/medicinedocs/documents/s23300e n/s23300en.pdf. Accessed on 13 November 2019.

Cite this article as: Punj V, Hakeem MA. Assessment of knowledge and reporting of adverse drug reaction in resident doctors in a teaching hospital in North India. Int J Basic Clin Pharmacol 2020;9:233-41. 


\section{APPENDIX}

\section{Demographics}

1. How old are you?
(a) 20 years
(b) 21-25 years
(c) 26-30 years
(d) 31-35 years
(e) 35 years

2. What is your sex?
(a) Male
(b) Female

3. Where did you do your undergraduate medical training?
(a) $\mathrm{CMC} \& \mathrm{H}$
(b) Other

4. If other, please name the institution?

Knowledge of adverse drug reactions (ADRs) and ADR reporting

5. Did you know the term ADRs before?
(a) Yes
(b) No

6. Have you witnessed any ADRs?
(a) Yes
(b) No

7. The likely cause of the ADRs was:
(a) drug-drug interaction
(b) medication error
(c) idiosyncratic reaction
(d) others (please specify)

8. If the above is yes, which of the following did it result in?
(a) No hospitalization
(b) Short hospitalization
(c) Prolonged hospitalization
(d) Morbidity
(e) Death

9. Do you consider the ADRs avoidable?
(a) Yes
(b) No

10. Do you consider the ADRs predictable?
(a) Yes
(b) No

\section{Did you report the ADRs?}
(a) Yes
(b) No

12. If the above is yes, whom did you report to?
(a) ADRs monitoring committee of the hospital
(b) National Pharmacovigilance Centre
(c) Head of department 
(d) Other (please specify)

13. Were you taught how to report ADR in your undergraduate CPT teaching?
(a) Yes
(b) No

14. Do you think a good knowledge of undergraduate CPT teaching would have improved the ADR reporting?
(a) Yes
(b) No

15. Has anybody ever discussed about ADR reporting with you in internship training?
(a) Yes
(b) No

16. Do you know about the Pharmacovigilance programme of India?
(a) Yes
(b) No

17. Any suggestions on improving ADR reporting knowledge by undergraduate training in clinical pharmacology and therapeutics? 